ICAASET-2021, 20-21 May, 2021, K.R. Mangalam University, Gurugram

International Journal of Technical Research \& Science (Special Issue) ISSN No.:2454-2024 (online)

\title{
POTENTIAL OF GREEN ENERGY GENERATION OF RIVER KHARKAI AT JAMSHEDPUR, JHARKHAND
}

\author{
Neetu Singh ${ }^{1}$, Binod Kumar Choudhary ${ }^{2}$ \\ E-Mail Id: neetu.envirohnbgu@gmail.com,dr.binod@arkajainuniversity.ac.in \\ ${ }^{1}$ Department of Environmental Sciences, HNB Garhwal University (A Central University) Srinagar- \\ Garhwal, Uttarakhand, India \\ ${ }^{2}$ Assistant Professor, Department of Engineering, School of Engineering \& IT, ARKA JAIN University, \\ Jamshedpur, Jharkhand, India
}

\begin{abstract}
Algal biomass is considered as best option for clean and green energy due to its fastest growth, sink for pollutants. This study deals with biofuel production from the algal biomass collected from River Kharkai at Jamshedpur, Jharkhand processed under laboratory. Chlorella vulgaris, Chlamydomonas rheinhardii , Botryococcus braunii, Scenedesmus sp.,Microcystis aeruginosa, Nitzschia sp. ,Cladophora sp. ,Porphyridium cruentum ,Zygnema sp. ,Spirogyra sp., Synechoccus sp are the major algal species recorded during study period that have biofuel generation capacity. An amount of $0.865 \mathrm{~g}^{\mathrm{dry}} \mathrm{wt} \mathrm{m}^{-2}$ algal biomass collected from the site. Soxhlet extraction method having chloroform: methanol (2:1) was used for Lipid extraction. 21.87\% of lipid was extracted from collected algal biomass. Extracted lipids were further hydrolyzed for release of fermentable sugar by trans-esterification and single step acid hydrolysis process. These fermentable sugars converted into an amount of $56.76 \%$ bioethanol which shows the green energy potential of River Kharkai.
\end{abstract}

Keywords: Algal Biomass, Green Energy, Bioethanol, River Kharkai.

\section{INTRODUCTION}

Sustainable world are stepping towards the production of green energy sources because fossil fuels creating load of $\mathrm{CO}_{2}$ and harmful gases in atmosphere and these non renewable energy resources going to be exhaust in future [1].Biomass is the answer for clean environment and energy sustainability [2]. One of most prominent biomass source which catches the attention of researcher throughout world is Algal biofuel because algal biomass supplied about $25 \%$ of global energy requirement [3]. Algal biomass has potential to produce a wide range of value-added products like biofuel, biofertilizer, bioactive compounds [2]. Algae have several advantages over other green sources like enormous biodiversity, fast growth rate, ability to grow in wastewater or wasteland, and act as sink for air pollutants [4-5]. All these advantages make the algal biomass an economically viable and an eligible candidate for the sustainable production of biofuel and green energy. Algae can form dense floating mats on water surfaces that make it suitable for cost-efficient biomass harvesting. Therefore, present study conducted to study the potential of green energy generated by algal biomass collected from River Kharkai, an tributary of Subarnarekha River, Jharkhand. This study has three specific objectives:

$>$ Water quality of River Kharkai

$>$ Extraction of lipids from harvested algal biomass.

$>$ Conversion of the lipid extracted algal biomass into Bioethanol via fermentable sugars

\section{MATERIALS AND METHODS}

Water samples and algal biomass were collected from River Kharkai near Adityapur Bridge, Jamshedpur, Jharkhand (Latitude $22.7892^{\circ} \mathrm{N}$; Longitude $86.1742^{\circ} \mathrm{E}$ ) from November- February 2020 during winter season when the growth is high as water is less turbulent. Standard Method followed for collection and testing [6-7]. Lipid extraction of algal biomass was done using Bligh and Dyer method [8] commonly called soxhlet method. Transesterification of extracted lipids into fatty acid methyl esters (FAMEs) done by methanolic sulphuric acid method [9]. Single step hydrolysis method used for acid hydrolysis. Acid hydrolysis product was used for sugar analysis by using fermentation process carried out for 7 days at $32^{\circ} \mathrm{C}$ with $\mathrm{pH} 5$. The fermented Product used for determination of Bioethanol concentration by using potassium dichromate method [10].

\section{RESULT AND DISCUSSION}

\subsection{Water Quality and Algal Biomass}

Changes in water quality of aquatic ecosystems have a substantial impact on the species that live within them. Seasonal variations in these parameters have an important role in the distribution and composition of freshwater biota [7] [11]. Water quality of River Kharkai was reported in Table 3.1. Dissolved oxygen decides ecological health of a fluvial ecosystem and protects aquatic life [7]. Dissolved oxygen was found $7.81 \mathrm{mg} . \mathrm{L}^{-1}$ and $\mathrm{pH}$ was observed 7.62 during study period. Alkaline water promotes high primary productivity [7]. Chlorophyceae has been recorded as the most dominant group in River Kharkai (Fig.1) followed by Bacillariophyceae and Cyanophyceae. Chlorophyceae is one of best algal group for biofuel production [12]. Chlorella vulgaris , Chlamydomonas rheinhardii, Botryococcus braunii, Scenedesmus sp., Microcystis aeruginosa, Nitzschia sp. ,Cladophora sp. ,Porphyridium cruentum ,Zygnema sp. ,Spirogyra sp., Synechoccus sp are the some major algal species were found during study period that have biofuel generation capacity. The oil content potential of these algal species was given in Table 3.2. An amount of total $0.865 \mathrm{~g} \mathrm{dry} \mathrm{wt} \mathrm{m}^{-2}$ of algal biomass harvested from River Kharkai for estimation of green energy potential. 
ICAASET-2021, 20-21 May, 2020, K.R. Mangalam University, Gurugram

International Journal of Technical Research \& Science (Special Issue) ISSN No.:2454-2024 (online)

Table-3.1 Water quality of River Kharkai

\begin{tabular}{|c|c|}
\hline Parameters & $($ Mean \pm SD $)$ \\
\hline Water Temperature $\left({ }^{0} \mathrm{C}\right)$ & $14.58 \pm 1.75$ \\
\hline Transparency (m) & $0.16 \pm 0.12$ \\
\hline Conductivity $\left(\mathrm{mS} . \mathrm{cm}^{-1}\right)$ & $0.56 \pm 0.03$ \\
\hline Turbidity (NTU) & $40.52 \pm 23.12$ \\
\hline pH & $7.62 \pm 0.14$ \\
\hline Dissolved Oxygen (mg.L $\left.\mathrm{L}^{-1}\right)$ & $7.81 \pm 1.12$ \\
\hline Alkalinity (mg.L $\left.{ }^{-1}\right)$ & $60.23 \pm 8.05$ \\
\hline Chlorides (mg.L L $^{-1}$ ) & $13.47 \pm 1.56$ \\
\hline Nitrates (mg.L.'-1) & $0.10 \pm 0.06$ \\
\hline Phosphates (mg.L $\mathrm{L}^{-1}$ ) & $0.06 \pm 0.04$ \\
\hline
\end{tabular}

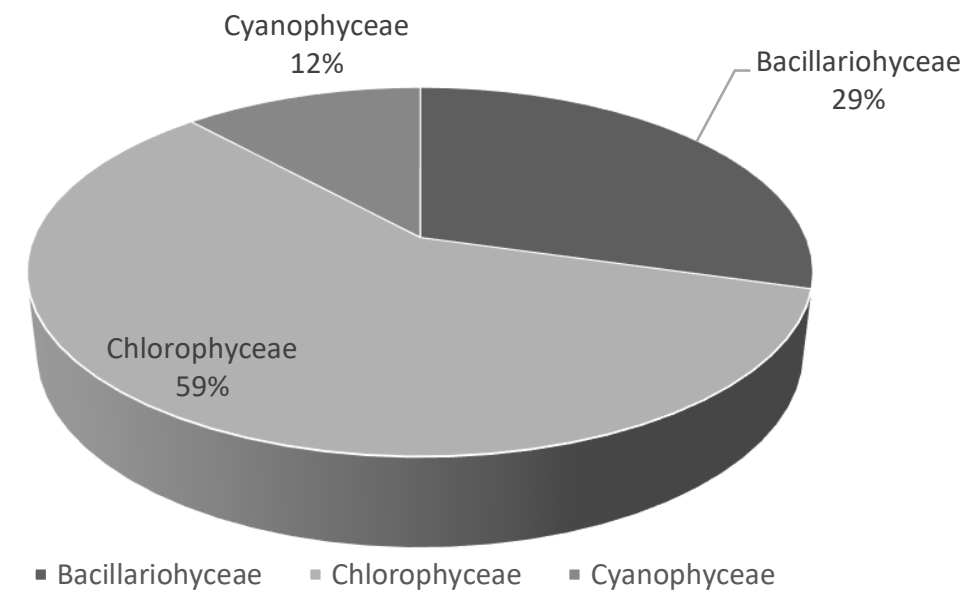

Fig. 3.1 Algal diversity of River Kharkai

Table-3.2 Oil content of harvested Algal species on dry weight basis

\begin{tabular}{|l|l|l|}
\hline Algal species & $\begin{array}{l}\text { Oil content } \\
\text { (\% dry weight })\end{array}$ & Reference \\
\hline Chlorella vulgaris & $28-32$ & {$[13]$} \\
\hline Chlamydomonas rheinhardii & 21 & {$[14]$} \\
\hline Botryococcus braunii & $29-75$ & {$[13]$} \\
\hline Scenedesmus sp. & 45 & {$[13]$} \\
\hline Microcystis aeruginosa & 30 & {$[15]$} \\
\hline Nitzschia sp. & $45-47$ & {$[13]$} \\
\hline Cladophora sp. & 3.5 & {$[14]$} \\
\hline Porphyridium cruentum & $9-14$ & {$[14]$} \\
\hline Zygnema sp. & 8.3 & {$[15]$} \\
\hline Spirogyra sp. & & {$[13]$} \\
\hline Synechoccus sp. & $11-21$ & {$[14]$} \\
\hline
\end{tabular}

3.2 Fatty acid methyl esters (FAMEs), Lipids, Sugar and Ethanol Production

Triglyceride (extracted lipids) was converted into Fatty acid methyl esters (Fig.3.2). An amount of total $21.87 \%$ of lipid was obtained from the collected algal biomass. The FAMEs were analyzed using gas chromatographymass spectroscopy (GC-MS) (Fig. 3) showed that major fatty acids that was obtained were saturated fatty acid (C16:0, C16:1, C18:0, C18:1,C18:2 and C18:3). Saturated Fatty acids (C16:1; C18:1 and C18:2) are considered to have major agent for algal biofuel production [13] [16]. 90\% of biofuel produced from C16 - C18 Fatty acid groups [17]. Major compositions of fatty acid methyl esters were given in Table 3.3.

DOI Number: https://doi.org/10.30780/specialissue-ICAASET021/006

pg. 32 
ICAASET-2021, 20-21 May, 2020, K.R. Mangalam University, Gurugram

International Journal of Technical Research \& Science (Special Issue) ISSN No.:2454-2024 (online)

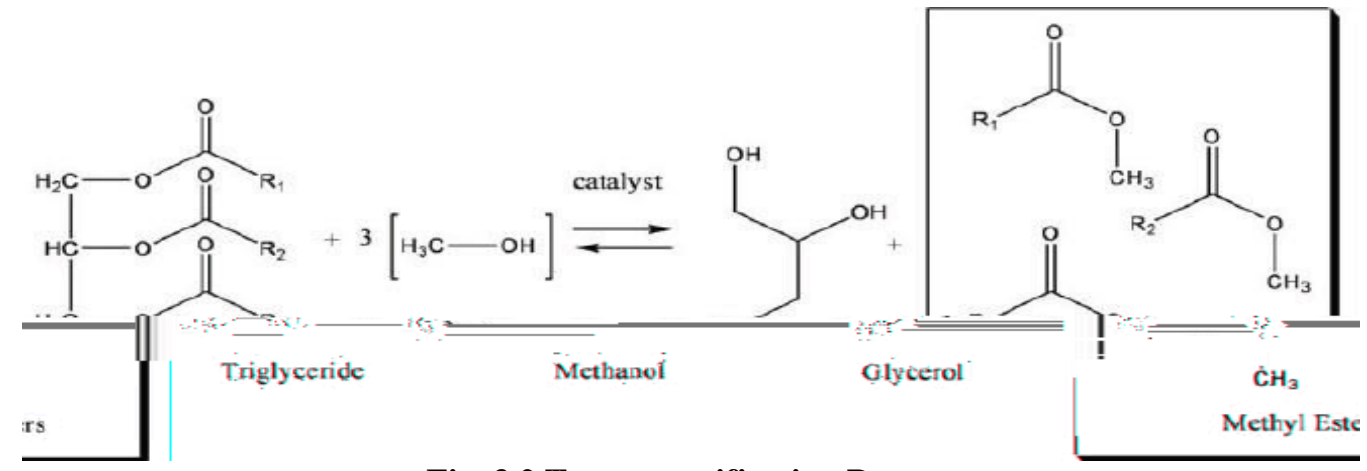

Fig. 3.2 Trans-esterification Process

Table-3.1 Major Fatty acid composition obtained during transesterification

\begin{tabular}{|l|l|l|}
\hline Fatty Acid Methyl Ester & Form & Mass\% \\
\hline Palmitic acid methyl ester & C16:0 & 8 \\
\hline Palmitoleic acid methyl ester & C16:1 & 20 \\
\hline Stearic acid methyl ester & C18:0 & 5 \\
\hline Oleic acid methyl ester & C18:1 & 30 \\
\hline Linoleic acid methyl ester & C18:2 & 15 \\
\hline Linolenic acid methyl ester & C18:3 & 10 \\
\hline Total Esters & & $\mathbf{8 8} \%$ \\
\hline
\end{tabular}

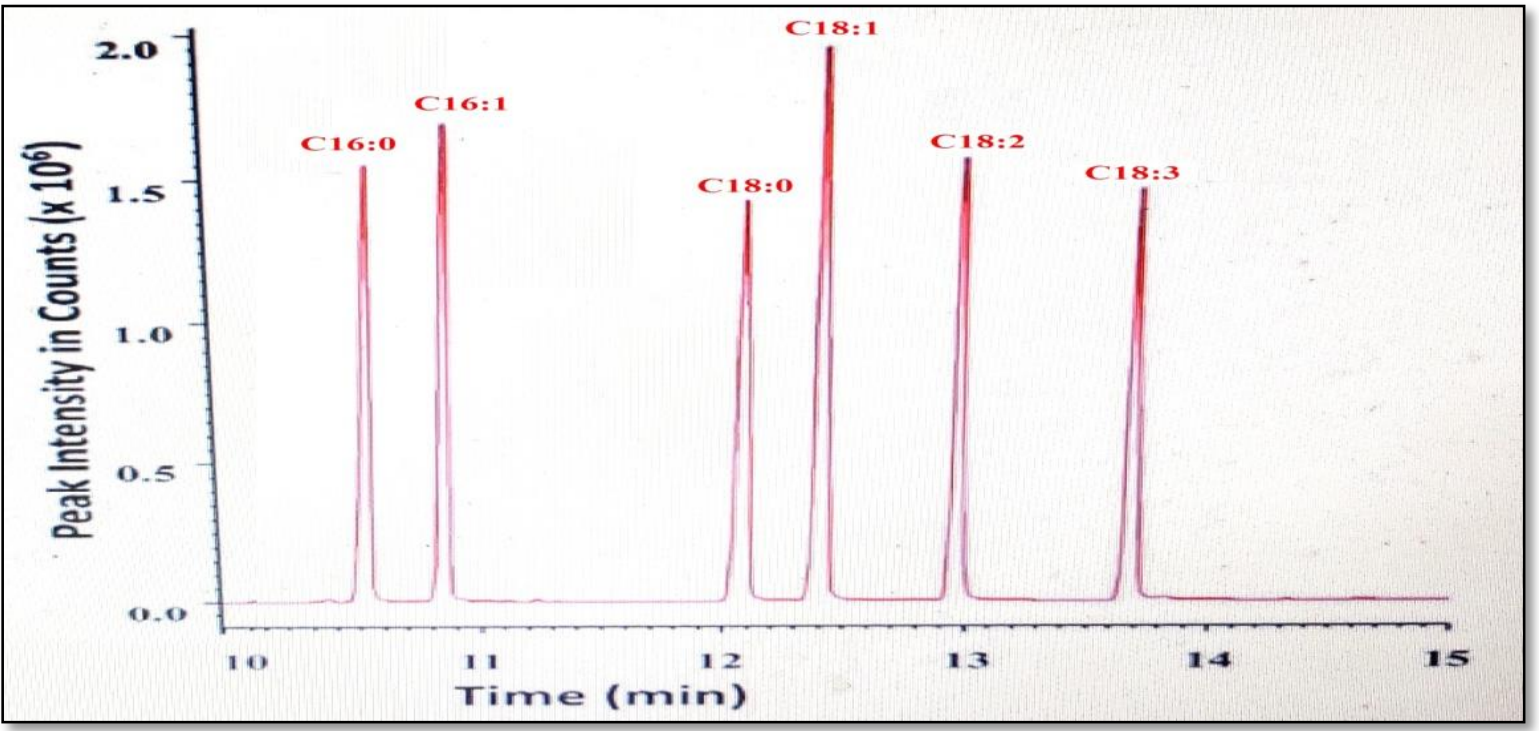

Fig. 3.3 GC-MS analysis of Fatty Acid Methyl Esters (FAMEs)

\subsection{Fermentable sugar and Bioethanol}

Single step hydrolysis method used for acid hydrolysis for the release of fermentable sugar. One-step acid hydrolysis method provides best results as compared to two-step approach for different biomass[ 18]. $\mathrm{H}_{2} \mathrm{SO}_{4}$ and $\mathrm{HCl}$ used for single step acid hydrolysis process. $\mathrm{H}_{2} \mathrm{SO}_{4}$ and $\mathrm{HCl}$ are powerful agents involve in hydrolysis of cellulose [19]. An amount of $38.5 \%$ sugar obtained from acid hydrolysis of extracted lipids obtained from dry algal biomass collected during study period. Sugar further utilized under fermentation process to produce bioethanol. Hence, total yield of bioethanol was recorded $56.75 \%$ from total collected algal biomass

\section{CONCLUSION}

This paper deals with the concept of green energy generation from algal biomass to promote environmental sustainability. The total $56.75 \%$ of bioethanol was recorded from the harvested $0.865 \mathrm{~g} \mathrm{dry} \mathrm{wt} \mathrm{m}^{-2}$ algal biomass. Algal biomass can play an important role in solving the problem between renewable and non-renewable energy sources in the near future. Algae also serve as better feedstock for many bioactive compounds. Algae considered as boon for River Kharkai because they act as sink for pollutants and treat the wastewater. Alkaline nature of water promotes algal growth. This study revealed that River Kharkai has immense potential of green energy generation and provides a base line data for future study. 
ICAASET-2021, 20-21 May, 2020, K.R. Mangalam University, Gurugram

International Journal of Technical Research \& Science (Special Issue) ISSN No.:2454-2024 (online) REFERENCES

[1] Singh, N., Choudhary, B.K. Fresh Water Algae: A Best Option for Renewable Energy Generation. In: Chattopadhyay J., Singh R., Prakash O. (eds) Renewable Energy and its Innovative Technologies. Springer, Singapore. (2019)89-97

[2] Ozturk, M.; Saba, N.; Altay, V.; Iqbal, R.; Hakeem, K.R.; Jawaid, M.; Ibrahim, F.H. Biomass and bioenergy: An overview of the development potential in Turkey and Malaysia. Renew. Sustain. Energy Rev. Vol.79. (2017) 1285-1302.

[3] Wolf. J., Ross. I.L., Radzun K.A., Jakob G., Stephens E., Hankamer B. High-throughput screen for high performance microalgae strain selection and integrated media design, Algal Res. (2015) 313-325

[4] Briens. C., Piskorz. J., Berruti. F. Biomass valorization for fuel and chemicals production - a review. International Journal of Chemical Reactor Engineering Vol.6 (2008) 1-52.

[5] Fulke. A.B., Mudliar S., Yadav R., Shekh A., Srinivasan N., Ramanan R.,. Krishnamurthi K, Devi S.S., Chakrabarti T., Bio-mitigation of $\mathrm{CO} 2$, calcite formation and simultaneous biodiesel precursors production using Chlorella sp, Bioresour. Technol. Vol.101 (2010) 1-49.

[6] APHA (American Public Health Association). Standard Methods for the Examination of Water and Waste Water, Washington, DC. $2005: 1-1368$

[7] Sharma., R.C., Singh, N., and Chauhan, A. The influence of physico-chemical parameters on phytoplankton distribution in a head water stream of Garhwal Himalayas: A case study. Egyptian Journal of Aquatic Research. Vol.42 (1), Elsevier, (2016),: 11-21.

[8] Bligh E.G., Dyer W.J., A rapid method of total lipid extraction and purification. Can. J. Biochem. Physiol. Vol. 37. (1959)913-917

[9] Kumar, V., Nanda, M., Verma, M. Application of agar liquid-gel transition in cultivation and harvesting of microalgae for biodiesel production. Bioresour Technol. Vol. 243 (2017)163-168

[10] Crowell, E.A., Ough, C.S., A modified procedure for alcohol determination by dichromate oxidation, Am. J. Enol. Viticult. Vol.30 (1979) 61-63.

[11] Singh, N., Sharma, R., C. Assessment of Physico-chemical parameters of Mountain River Baldi, Garhwal Himalayas. Inter.J. of Fisheries and Aquatic Studies, Vol.4(2) (2016)88-93.

[12] Demirbas, A., Demirbas, M. F., Importance of algae oil as a source of biodiesel. Energ. Convers. Manage. Vol.52 (2011) 163-170.

[13] Kumar, P., Mathew, L., Shimi, S. L., \& Singh, P. (2016). Need of ICT for Sustainable Development of Power Sector. Proceedings of International Conference on ICT for Sustainable Development, 607-614. doi:10.1007/978-981-10-0129-1_63.

[14] K. Sharma, S. K. Goyal, P. Kumar, and P. Singh, "Placement of D-FACTs in Distribution Network with the Accommodation of DER," ETPEEES-2014, Krishi Sanskriti at Jawahar Lal Nehru University, New Delhi, 21-22 June 2014, pp. 283-289.

[15] P. Kumar and V. Kumar, "Energy storage options for enhancing the reliability of Power system in the presence of Renewable Energy Sources," 2020 Second International Conference on Inventive Research in Computing Applications (ICIRCA), Coimbatore, India, 2020, pp. 1071-1076, doi: 10.1109/ICIRCA48905.2020.9183349.

[16] Chisti, Y. Biodiesel from microalgae. Biotechnology Advances, Vol.25 (2007) 294-306

[17] Sydney, E.B. Sturm, W. de Carvalho, J.C. Thomaz-Soccol, V. Larroche, C. Pandey, A., Soccol, C.R. Potential carbon dioxide fixation by industrially important microalgae. Bioresource Technology. Vol 101 (2010) 5892-5896.

[18] Abdo, S.M., Ahmed, E., El-Enin, S., A.,Rawheya S. El Din et al. Qualitative and quantitative determination of lipid content in microalgae for biofuel production. Journal of Algal Biomass Utilization. Vol. 5 (3) (2014) 23- 28

[19] Halim R., Gladman B., Danquah M., Webley P., Oil extraction from microalgae for biodiesel production. Bioresour Technol. Vol 102 (2011) 178-85.

[20] Gupta, V. K., Tuohy, M., Kubicek, C. P., Saddler, J., Feng, X. Bioenergy Research: Advances and Applications, 1st Edition, Elsevier, London, 2014.

[21] Miller G. L.. Use of dinitrosalicylic acid reagent for determination of reducing sugar, Anal Chem. 31( 1959) 426-428.

[22] Sun. Y., Cheng. J., Hydrolysis of lignocellulosic materials for ethanol production: a review, Bioresour Technol. Vol. 83 (2002)1-11. 